NOAA

National Marine

Fisheries Service
Fishery Bulletin

¿ established 1881 ๙
Spencer F. Baird

First U.S. Commissione of Fisheries and founder of Fishery Bulletin

\begin{abstract}
The purpose of this study, conducted from 2012 through 2014, was to gather data on the different effects of circle and $J$ hooks on hooking outcome, frequency of deep hooking, and catch rate in the recreational shark fishery off Maryland. Circle hooks clearly outperformed $\mathrm{J}$ hooks. Interactions of sharks with circle hooks resulted in a $91 \%$ hooking rate (of which $3 \%$ were deep hookings), an $88 \%$ capture rate, and a catch rate of 0.9 sharks/hook interaction. The hooking rate for $\mathrm{J}$ hooks was $75 \%$ (of which 6\% were deep hookings), a capture rate of $68 \%$, and a catch rate of 0.7 sharks/hook interaction. These results indicate that circle hooks can improve fishing success and serve as a conservation measure by maximizing the probability of survival for sharks during recreational shark fishing.
\end{abstract}

Manuscript submitted 31 August 2015. Manuscript accepted 6 June 2016.

Fish. Bull. 114:370-372 (2016).

Online publication date: 21 June 2016. doi: 10.7755/FB.114.3.9

The views and opinions expressed or implied in this article are those of the author (or authors) and do not necessarily reflect the position of the National Marine Fisheries Service, NOAA.

\title{
A comparison of circle hook and $J$ hook performance in the recreational shark fishery off Maryland
}

\author{
Angel L. Willey (contact author) \\ Linda S. Barker \\ Mark Sampson \\ Email address for contact author: angel.willey@maryland.gov \\ Fisheries Service \\ Maryland Department of Natural Resources \\ 580 Taylor Avenue \\ Annapolis, Maryland 21401
}

Numerous studies of the recreational use of circle hooks in teleost fisheries and the commercial pelagic longline fishery indicate that fewer fish are "deep hooked" on circle hooks and that catch efficiency with circle hooks is equal to, or better than, that with J hooks (Cooke and Suski, 2004; Serafy et al., 2012). These studies have helped circle hooks gain acceptance and have provided the data used to set forth regulatory requirements for some fisheries and tournaments (Cooke and Suski, 2004). In the recreational shark fishery, some anglers have been reluctant to switch to circle hooks because of concerns about catch efficiency and doubts about the applicability of the results of teleost studies to the catchability of sharks (Prince et al., 2002; Lucifora et al., 2009; Serafy et al., 2012). Therefore, scientific evidence that supports the benefits of circle hooks is needed to convince recreational shark anglers to voluntarily switch hook types and support regulatory measures that require circle hook use in their fishery. We undertook this study from 2012 through 2014 to gather data on the effects of circle and $J$ hooks on hooking outcome, frequency of deep hooking, and catch rate in the recreational shark fishery off Maryland.

\section{Materials and methods}

Field methods

All data were collected by a charter captain that specialized in shark fishing off the Atlantic coast of Maryland. He fished as he normally did but dedicated 2 surface lines to our study, set with a circle hook and a comparable-size J hook. Circle hooks were limited to Mustad ${ }^{1}$ 39960D hooks in sizes $16 / 0$ when fishing occurred offshore and 13/0 when fishing occurred nearshore (O. Mustad \& Son A.S., Gjovik, Norway). Bait type was identical in size and species for both lines and was refreshed at the same time.

The outcome of each shark interaction with the line (called a strike) was recorded as a bite, as lost, or as captured)-terminology similar to that of Skomal et al. (2002). A bite was defined as a strike that resulted in the shark taking the bait but not being hooked. An event was not recorded if the captain or mate

\footnotetext{
${ }^{1}$ Mention of trade names or commercial companies is for identification purposes only and does not imply endorsement by the Maryland Department of Natural Resources.
} 


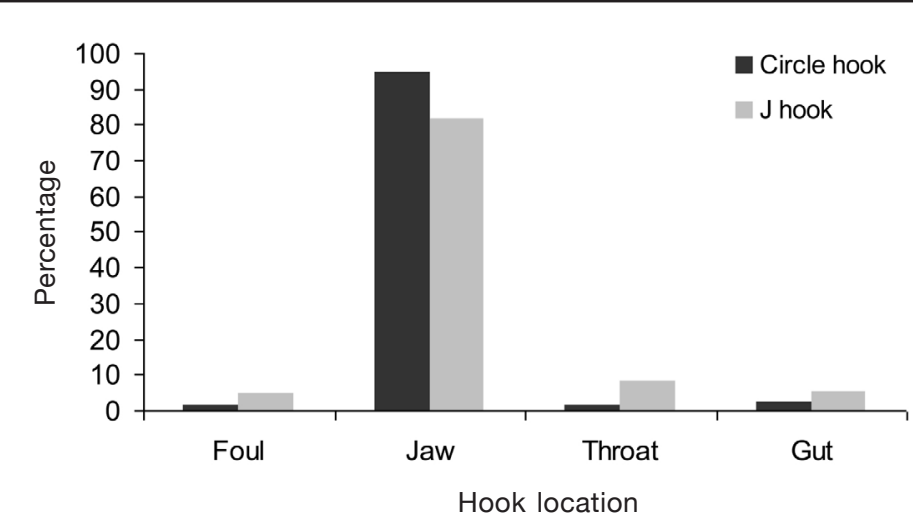

Figure 1

Hook locations ( $n=622$ ) observed, 2012-2014, during a study of interactions of sharks with circle and $J$ hooks in the recreational shark fishery off Maryland. Data for 2 landed sharks were not included in this figure because either a hook location was not recorded or the shark had become entangled in the line and a hooking event did not occur. A location at throat or gut was considered a deep hooking.

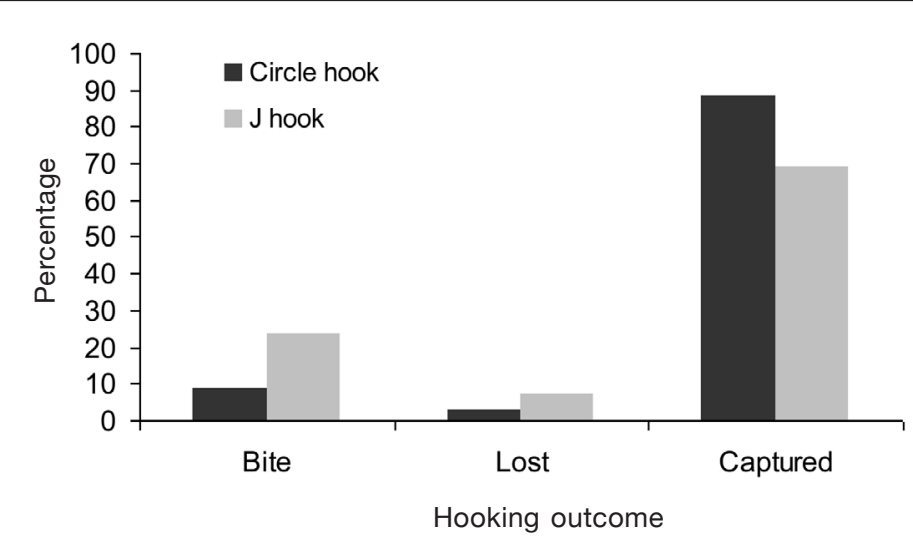

Figure 2

Outcomes of hooking events ( $n=781$ ) observed during 2012-2014 as part of a study of interactions of sharks with circle and $J$ hooks in the recreational shark fishery off Maryland, classified into 3 categories: 1) bite, when a shark took the bait but was not hooked; 2) lost, when a hooked shark became unhooked before the mate could grab the leader; and 3) captured, when a shark was fully played to the boat and the mate grabbed the leader.

could not confirm that it was a shark bite. A lost classification was defined as the outcome where a hooked shark became unhooked before the mate could grab the leader. A captured classification was the outcome when a shark was fully played to the boat and the mate grabbed the leader. Hook location was recorded as jaw, throat, gut, or foul (external). Entangled fish were documented but excluded from the analysis because they were not actually hooked. Deep hooking was defined as hooking in the throat or gut.

\section{Statistical methods}

Trips were identified as nearshore or offshore because of differences in species composition and tackle requirements. Nearshore trips occurred in waters within $32.2 \mathrm{~km}$ (20 mi) of land, and offshore trips took place in waters 32.2 or more kilometers from land. Most of the nearshore fishing occurred within $1.6-9.7 \mathrm{~km}$ (1-6 $\mathrm{mi}$ ) of the beach, and the majority of offshore fishing took place between 32.2 and 48.3 $\mathrm{km}(20$ and $30 \mathrm{mi}$ ) from the beach.

Data were pooled across years, and the following tests were performed. Chi-square analysis was used to determine whether nearshore and offshore trip data could be pooled. Hypothesis tests of proportions were conducted to compare hooking outcomes and to compare rates of deep hooking between hook types. Catch rate was defined as the number of sharks captured per interaction and calculated as the mean of trip values. Student's $t$-test was used to compare catch rates between hook types.

\section{Results}

Data were collected during 24 offshore and 180 nearshore trips, and the results of chisquare analysis indicated that nearshore and offshore data could be pooled for all analyses (all $P>0.10$ ). During this study, 624 sharks representing 10 shark species were captured, primarily dusky shark (Carcharhinus obscurus; $n=235$ ), spinner shark (Carcharhinus brevipinna; $n=180$ ), sandbar shark (Carcharhinus plumbeus; $n=89$ ), and Atlantic sharpnose shark (Rhizoprionodon terraenovae; $n=70$ ). The other species caught were the blue shark (Prionace glauca; $n=15$ ), blacktip shark (Carcharhinus limbatus; $n=13$ ), tiger shark (Galeocerdo cuvier; $n=7$ ), shortfin mako (Isurus oxyrinchus; $n=7$ ), scalloped hammerhead (Sphyrna lewi$n i ; n=5$ ), and smooth hammerhead (Sphyrna zygaena; $n=3)$.

There were 438 shark interactions with circle hooks and 343 interactions with J hooks. Interactions with circle hooks resulted in a $91 \%$ hooking rate of which $95 \%$ of sharks were hooked in the jaw and only $3 \%$ were deep hookings (Fig. 1). Circle hooks had an $88 \%$ capture rate (Fig. 2 ) and a catch rate of 0.9 sharks/hook interaction. For $\mathrm{J}$ hooks, the hooking rate was $75 \%$ of which $82 \%$ of sharks were hooked in the jaw and 6\% deep hookings. The capture rate was $68 \%$ and the catch rate was 0.7 sharks/hook interaction. All differences were significant with $P<0.01$. 


\section{Discussion}

The data clearly indicate that circle hooks outperform J hooks. Circle hooks had both a higher hooking rate and capture rate than $\mathrm{J}$ hooks. Circle hooks had a lower deep-hooking rate and a higher proportion of sharks hooked in the jaw-results that are consistent with those of many teleost studies (Prince et al., 2002; Skomal et al., 2002). Both the higher catch rate and the lower deep-hooking rate indicate that circle hooks can improve fishing success and serve as a conservation measure for recreational shark fishing. In addition, the results of this study indicate that the use of circle hooks could increase adherence to the federal regulations regarding prohibited shark species-regulations that are outlined in a compliance guide for highly migratory species $\left(\mathrm{NMFS}^{2}\right)$. These regulations require that shark species for which retention is prohibited be released in a manner that maximizes the probability of their survival.

\footnotetext{
2 NMFS (National Marine Fisheries Service). 2015. HMS recreational compliance guide: guide for complying with the Atlantic billfishes, swordfish, sharks, and tunas regulations, p. 30. Off. Sustainable Fish., Highly Migratory Species Manage. Div., Natl. Mar. Fish. Serv., NOAA, Silver Spring, MD. [Available at website, accessed June 2016.]
}

\section{Acknowledgments}

We would like to thank the 3 anonymous reviewers for their constructive comments at the manuscript stage.

\section{Literature cited}

Cooke S. J., and C. D. Suski.

2004. Are circle hooks an effective tool for conserving marine and freshwater recreational catch-and-release fisheries? Aquat. Conserv. 14:299-326. Article

Lucifora, L. O., V. B. Garcia, and A. H. Escalante.

2009. How can the feeding habits of the sand tiger shark influence the success of conservation programs? Anim. Conserv. 12:291-301. Article

Prince, E. D., M. Ortiz, and A. Venizelos.

2002. A comparison of circle hook and "J" hook performance in recreational catch-and-release fisheries for billfish. Am. Fish. Soc. Symp. 30:66-79.

Serafy, J. E., S. J. Cooke, G. A. Diaz, J. E. Graves, M. Hall, M. Shivji, and Y. Swimmer.

2012. Circle hooks in commercial, recreational, and artisanal fisheries: research status and needs for improved conservation and management. Bull. Mar. Sci. 88:371391. Article

Skomal, G. B., B. C. Chase, and E. D. Prince.

2002. A comparison of circle hook and straight hook performance in recreational fisheries for juvenile Atlantic bluefin tuna. Am. Fish. Soc. Symp. 30:57-65. 